\title{
Stock market and aggregate consumption asymmetry: evidence from Malaysia
}

\begin{abstract}
Purpose $i$ The purpose of this paper is to analyze the influences of real share prices on aggregate consumption for Malaysia with the focus on whether there is asymmetry in the long-run relation of the two variables.

Design/methodology/approach $\ddot{i}$ The paper specifies aggregate consumption to depend on real income and real share prices. Alternatively, imposing long-run budget constraint, the paper specifies the relation between aggregate consumption and real share prices as ratio to real income. Then, it applies an asymmetric cointegration and error correction modeling.

Findings $\ddot{i}$ The cointegration tests indicate the presence of a long-run relation between consumption-income ratio and share price-income ratio. More interestingly, while changes in share prices exert short-run causal influences on Malaysiaôs private consumption, evidence is found for the adjustments of consumption $\ddot{i}$ income ratio to the long-run equilibrium path only when it is above its long-run value. The paper interprets the finding as suggesting downward revisions in the consumption patterns when there are adverse shocks in share prices and accordingly, supports the existence of especially negative wealth effect for Malaysia.

Research limitations/implications $\ddot{i}$ Owing to data limitations, the paper relies on aggregate consumption and aggregate income data. It acknowledges that the sum of non-durable consumption and flow-of-services from durable purchases and labor income are more appropriate measures of, respectively, consumption and real income.

Originality/value $\ddot{i}$ The findings have important implications for understanding consumption behavior in a developing country and can provide insight on the effectiveness of monetary policy.
\end{abstract}

Keyword: Consumption; Stock markets; Malaysia; Share prices; Modelling 